\title{
Differential hierarchical metabolites expression of red/white Salacca sumatrana arillus and its molecular docking studies
}

\author{
MIFTAHUL HUDA FENDIYANTO ${ }^{1,2, \vartheta}$, RIZKY DWI SATRIO ${ }^{1,2}$, I DEWA KETUT KERTA WIDANA ${ }^{3}$, \\ MENTARI PUTRI PRATAMI ${ }^{1}$, ISNA AROFATUN NIKMAH ${ }^{1}$, DIDI DARMADI ${ }^{4}$ \\ ${ }^{1}$ Department of Biology, Universitas Pertahanan Indonesia. Kampus Universitas Pertahanan, Sentul, Bogor 16810, West Java, Indonesia. \\ Tel.:+62-21-87951555 ext.7001, `email: miftahul.fendiyanto@idu.ac.id \\ ${ }^{2}$ Laboratory of Plant Physiology and Molecular Biology, Department of Biology, Faculty of Mathematics and Natural Sciences, Institut Pertanian Bogor. \\ J1. Agatis, IPB University Campus Darmaga, Bogor 16680, West Java, Indonesia \\ ${ }^{3}$ Disaster Management Program, Universitas Pertahanan Indonesia. Kampus Universitas Pertahanan, Sentul, Bogor 16810, West Java, Indonesia \\ ${ }_{4}^{4}$ Indonesian Agency for Agricultural Research and Development, Ministry of Agriculture. Jl. Pang Nyak Makam No. 27, Banda Aceh 24415, Aceh, \\ Indonesia
}

Manuscript received: 20 December 2020. Revision accepted: 25 January 2021

\begin{abstract}
Fendiyanto MH, Satrio RD, Widana IDKK, Pratami MP, Nikmah IA, Darmadi D. 2021. Differential hierarchical metabolites expression of red/white Salacca sumatrana Arillus and its molecular docking studies. Biodiversitas 22: 1014-1024. Salak Sidempuan (Salacca sumatrana) is one of the medicinal plants originating from tropical countries. However, there is very little research on the study of finding bioactive compounds in $S$. sumatrana using the metabolomic approach. Here, we use two population types of $S$. sumatrana, e.g., fruit with red and white arillus. We extracted the compounds from the two tissues using the GC-MS technique and further analyzed their antiviral potential using an in-silico molecular docking technique. Fold change analysis showed that in white arillus there were 21 upregulated compounds and 25 downregulated compounds. Metabolites that have high expression in white arillus tissue are ranxinic acid, nicotinic alcohol, stearic acid, 2-furan carboxaldehyde, and others. Six accessions from S. sumatrana based on PCA analysis and separate dendrogram according to the type of arillus, i.e., red and white arillus. Two compounds that act as antivirals found in this study are stearic acid and palmitic acid based on preliminary molecular docking studies. These two compounds could be used for further studies as a preventive measure against SARS-Cov-2 in the future, however, it needs further comprehensive and clinical analysis the future. In conclusion, metabolites in white arillus were distinctly different from red arillus of snake fruits (salaks). In addition, studies on differential metabolite expression on two types of arillus (red/white) can be used as markers in identifying arillus color early by plant breeders.
\end{abstract}

Keywords: Arillus, differential metabolites expression, metabolomics, preventive-antiviral

\section{INTRODUCTION}

Snake fruit or salak is a tropical fruit that is in great demand and is edible in tropical countries, especially in Indonesia. The part that is eaten by humans is the arillus, where the arillus in the Salacca fruit can be distinguished, one of which is the arillus color, i.e., red or white arillus. Based on the color of arillus, it can be divided into two types, namely red arillus and white arillus. In one species, e.g., Salacca sumatrana (Becc.) Mogea has two types of arillus; they are white and red arillus (Yuliamita 2014; Harahap and Ardiarini 2018). In the same species but having two different kinds of characteristics, it can be said that these characters are included in the subspecies distinguishing features. Determination of subspecies differentiating features can be supported by morphological, anatomical, molecular, or metabolite approaches (Yuliamita 2014; Harahap and Ardiarini 2018; Zhang et al. 2018; Pratami et al. 2019; Satrio et al. 2019; Nikmah et al. 2020; Fendiyanto et al. 2020). Determining the distinguishing features of the arillus in S. sumatrana has its challenges due to different physiological factors. Different physiological processes can be caused by differences in metabolism between white and red arillus. Fendiyanto et al.
(2020) found that significant metabolic pathways in the red arillus of $S$. sumatrana is sulfur catabolism, pyruvate metabolism, and fatty acid biosynthesis. However, there are no metabolic profiling studies on the white arillus of $S$. sumatrana. Thus, a comparative metabolite study between white and red arillus is necessary.

Metabolite markers are distinguishing features that can differentiate at the level of family, genus, species, subspecies, population, and accession (Do Amaral et al. 2016). Metabolite markers may be influenced by the environment and plant stress levels (Nguyen et al. 2001; Nguyen et al. 2003; Do Amaral et al. 2016; Zhang et al. 2018). However, by looking at the metabolite profile broadly, the metabolite can be used as a marker with relatively stable conditions and is found in several different populations and a relatively high number of samples. The use of metabolite markers to differentiate several populations has been carried out by Quinet et al. (2012), was conducted to differentiate the level of tolerance to certain stresses. Metabolite markers can also be used to distinguish different metabolic differences in organisms (Quinet et al. 2012; Yuliamita 2014; Jorge et al. 2016; Hiremath et al. 2017; Zhang et al. 2018; Fendiyanto et al. 2020). The use of metabolite markers to distinguish white 
and red arillus accessions has never been carried out, meanwhile, the coloration of salak arillus is relatively dependent on the metabolite profile and metabolic and physiological processes of arillus formation. Thus, it is important to determine metabolite markers in plants (Joyard and Douce 1987).

Research on metabolite markers can be carried out using the HPLC, GC-MS, and LC-MS techniques (Tyagi and Agarwal 2017). Metabolite marker studies can be done by doing hierarchical differential metabolite expression (HDME) and the correlation has been done in several plants such as rice, corn, Arabidopsis, wheat, tea, coffee, beans, and berries as well as several animals such as chickens, cows, chimpanzees, and human. The study of HDME between white and red arillus in S. sumatrana has never been done, therefore this study aimed to compare white and red arillus accessions in S. sumatrana using a hierarchical differential metabolite expression (HDME) technique. based on GC-MS Instruments.

\section{MATERIALS AND METHODS}

\section{Physiological development}

Salacca sumatrana (Becc.) Mogea was collected from Medan, North Sumatra, Indonesia. The fruit used consists of two kinds, namely $S$. sumatrana with red and white arillus, where each sample consists of three accessions each. The accessions used in this study were R1, R2, R3, $\mathrm{W} 1, \mathrm{~W} 2$, and $\mathrm{W} 3$ where the six accessions were taken from different populations, allowing the metabolite data taken to be independent of environmental factors. We have collected six biological and technical replications of fruits (red/white arillus) in each accession. Each S. sumatrana fruit size that was collected has 100-105 $\mathrm{g}$ in weight, 11-13 $\mathrm{cm}$ in height, freshly appearance, and mature ripening in the developmental stage, especially characterized by a fragrant and slightly soft fruity aroma. The fruit was harvested with relatively the same characteristics, size, and phase of fruit development in each accession. When harvested, the fruit was put into liquid nitrogen, put in an icebox, and then stored at $-80{ }^{\circ} \mathrm{C}$ in the freezer.

\section{Analysis of gas chromatography-mass spectrometry (GC-MS)}

GC-MS analysis was carried out by following Fendiyanto et al. (2020) and Pratami (2020) with minor modifications. A total of 5 grams of arillus was extracted using methanol $\left(50 \mathrm{ml}\right.$ solvent) at $25{ }^{\circ} \mathrm{C}$ for $72 \mathrm{~h}$, shaken with a $50 \mathrm{rpm}$ shaker (proportion: $1 \mathrm{~g}$ sample:10 $\mathrm{ml}$ solvent), modified by Park et al. (2019) and Fendiyanto et al. (2020). The extract was then evaporated for $60 \mathrm{~min}$ using an evaporator (Caliper-Life-Science, USA) at $45^{\circ} \mathrm{C}$. The samples were then freeze-dried and stored at $-80{ }^{\circ} \mathrm{C}$ before derivatization. We performed the sample derivatization procedures for GC-MS analysis using a tutorial metabolomics study (Mastrangelo et al. 2015; Park et al. 2019). We added directly $100 \mu$ of O-methoxyamine hydrochloride (Sigma-Aldrich, Madrid, Spain) in pyridine (concentration: $20 \mathrm{mg} / \mathrm{mL}$ ) to all lyophilized samples. The mix was then vortex for ten minutes and briefly incubated at $25{ }^{\circ} \mathrm{C}$ for $16 \mathrm{~h}$. As much as $100 \mu \mathrm{l}$ of $\mathrm{N}$, O-bis(trimethylsilyl)-trifluoroacetamide containing $1 \%$ trimethylchlorosilane was briefly added into the sample. The samples then were derivatized at $70{ }^{\circ} \mathrm{C}$ for $1 \mathrm{~h}$ and the mixture was incubated at $25^{\circ} \mathrm{C}$ for $1 \mathrm{~h}$ in dark conditions. We added $600 \mu \mathrm{l}$ of methyl stearate in heptane, concentration $100 \mathrm{ppm}$, into the solution. Each mixture was centrifuged at $13,000 \mathrm{rpm}$ for $10 \mathrm{~min}$ to remove precipitates following Park et al. (2019). The supernatant was then directly transferred to a chromatographic vial and injected into the GC-MS instrument. The extract $(5 \mu \mathrm{l})$ in split is then injected into the GC-MS Instrument with the following equipment specifications: main instrument (7890, Agilent Tech-Palo Alto-USA), auto-sampler (7693, Agilent Tech-Palo Alto-USA), Mass Selective Detector, and a Chemstation Dataset System (5975 inert MSD Detector, Agilent Tech-Palo Alto-USA). Instruments covering injection temperature and temperature of various instruments, mass spectrum detection, and metabolite identification were carried out following Fendiyanto et al. 2020. Instruments settings in this study were $230^{\circ} \mathrm{C}$ of ion source temperature, $250^{\circ} \mathrm{C}$ of injection temperature, $140^{\circ} \mathrm{C}$ of quadrupole temperature, and $280^{\circ} \mathrm{C}$ of interface temperature. We also used HP ultra-2 column capillary with $0.11 \mu \mathrm{m}$ in size. We performed a carrier gas instrument using $1.2 \mathrm{ml} / \mathrm{min}$ of a flow rate of Helium. The obtained mass spectrum was analyzed in a mass-to-charge range of $20-500 \mathrm{~m} / \mathrm{z}$. The detected metabolites were investigated according to the Wiley W8N08.L database.

\section{Statistical and integrative analysis of metabolomics data}

We used calibration curves to determine the absolute concentrations (Figure 1) of the metabolites and performed hierarchical expression analysis using Metaboanalyst R versions 4.0 (Pang et al. 2020). The MetaboAnalyst data was tested with a fold change approach using MetaboAnalyst software (Xia and Wishart 2016) with settings namely analysis type "unpaired", fold change threshold "2", comparison type "White / Red", and significant count threshold "75\%". For correlation analysis, we use the settings, namely dimension 'feature', distance measure 'Spearman rank correlation', view mode 'overview', color contrast 'red/green', fix color distribution 'false', clustering 'false'. For heatmap analysis, we use settings, namely distance measure 'Euclidian', clustering algorithm 'single', color contrast 'red/green', data source 'normalized data', standardization 'autoscale features', view mode' overview with T-test / ANOVA ', view option' false '. All metabolite data were compared with the KEGG database, HMDB (Wishart et al. 2018), Pubchem followed Fendiyanto et al. (2020). Metabolites were analyzed using univariate and multivariate data (Fendiyanto et al. 2019a; Fendiyanto et al. 2019b; Satrio et al. 2019) using R version 3.5.1 (Lander 2014) and MetaboAnalystR version 4.0 (Chong et al. 2018; Chong and Xia 2018; Chong et al. 2019; Pang et al. 2020). To make Venn diagrams, we performed VENNY version 2.1 (https://bioinfogp.cnb.csic.es/tools/ve nny/). 


\section{Comparative studies and molecular docking of metabolites compounds}

Metabolomics data were obtained, analyzed, and compared with Pharmacophore Modeling and Molecular Docking data from Erlina et al. (2020). Metabolomics data that have potential as herbs in inhibiting the Coronavirus, especially the 3CLPro, PLPro, and RdRp proteins. The matched metabolites were then identified the binding energy value and further characterized the metabolite 3Dstructure crystallography using the Pubchem, KEGG, and HMDB metabolite databases following Fendiyanto et al. (2020). Metabolites-molecular docking of S. sumatrana arillus was performed using a computer (macOS Mojave version 10.14.6, 2.3 GHz Intel Core i9 Processor, and 16 GB $2400 \mathrm{MHz}$ DDR4 memory). We have validated the data using AutoDock 4 Software.
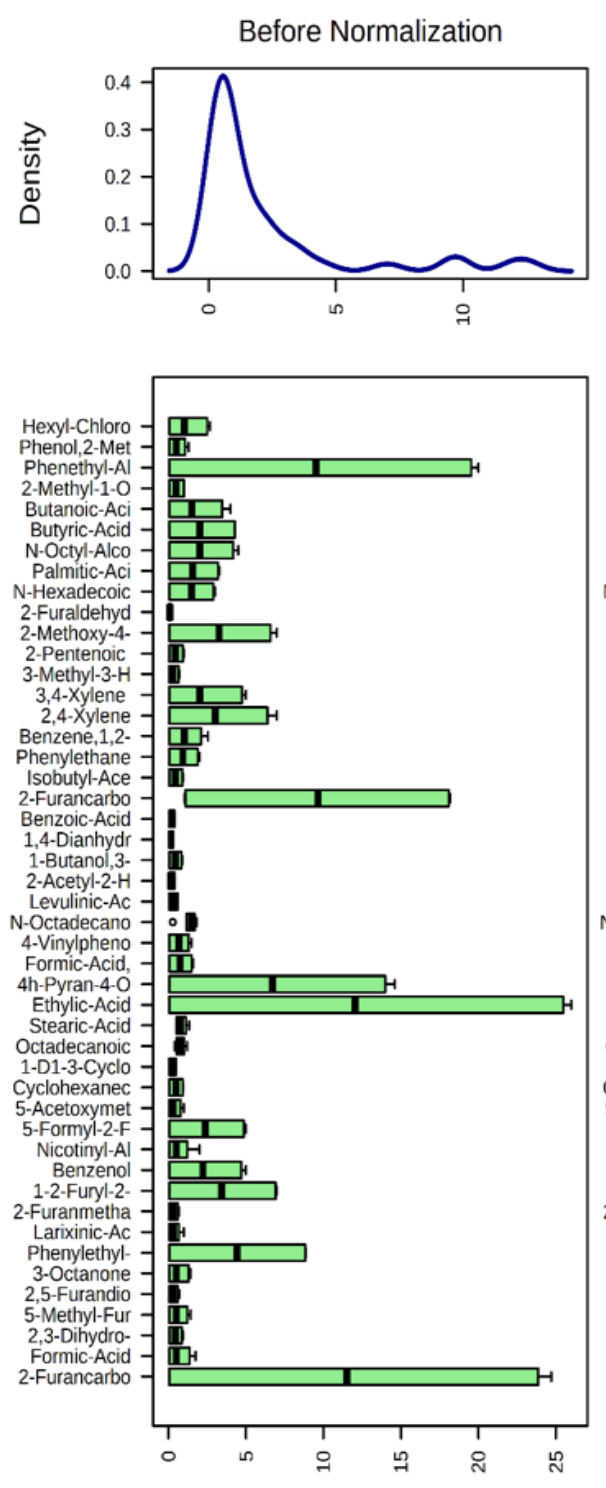

Concentration

\section{RESULTS AND DISCUSSION}

\section{The concentration of each metabolite}

The concentration of metabolites in the arillus of $S$. sumatrana showed a significant difference, allowing the normality curve to be abnormal. In this study, the normality curve before being transformed, the concentration showed a range from 0 to 25 , while after being transformed it ranged from -10 to +10 . After transformation, the metabolite concentrations show a normally distributed curve (Figure 1), indicating that the metabolites analyzed meet the statistical rules and can be continued for heatmap analysis and T-test. Venn Diagram showed that many metabolites were significantly different among Arillus accession, but looks similar within white or red samples (Figure 2).
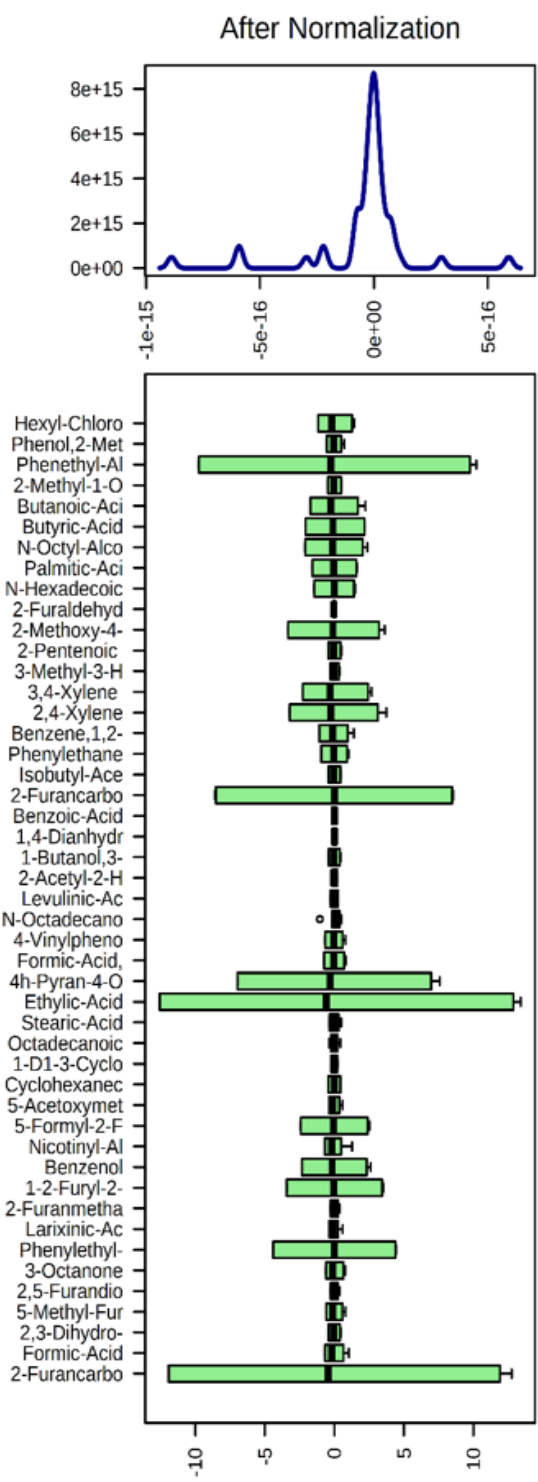

Normalized Concentration

Figure 1. Data processing of Salacca sumatrana metabolites. All metabolite data were normalized using Metaboanalyst. R using main centered default 

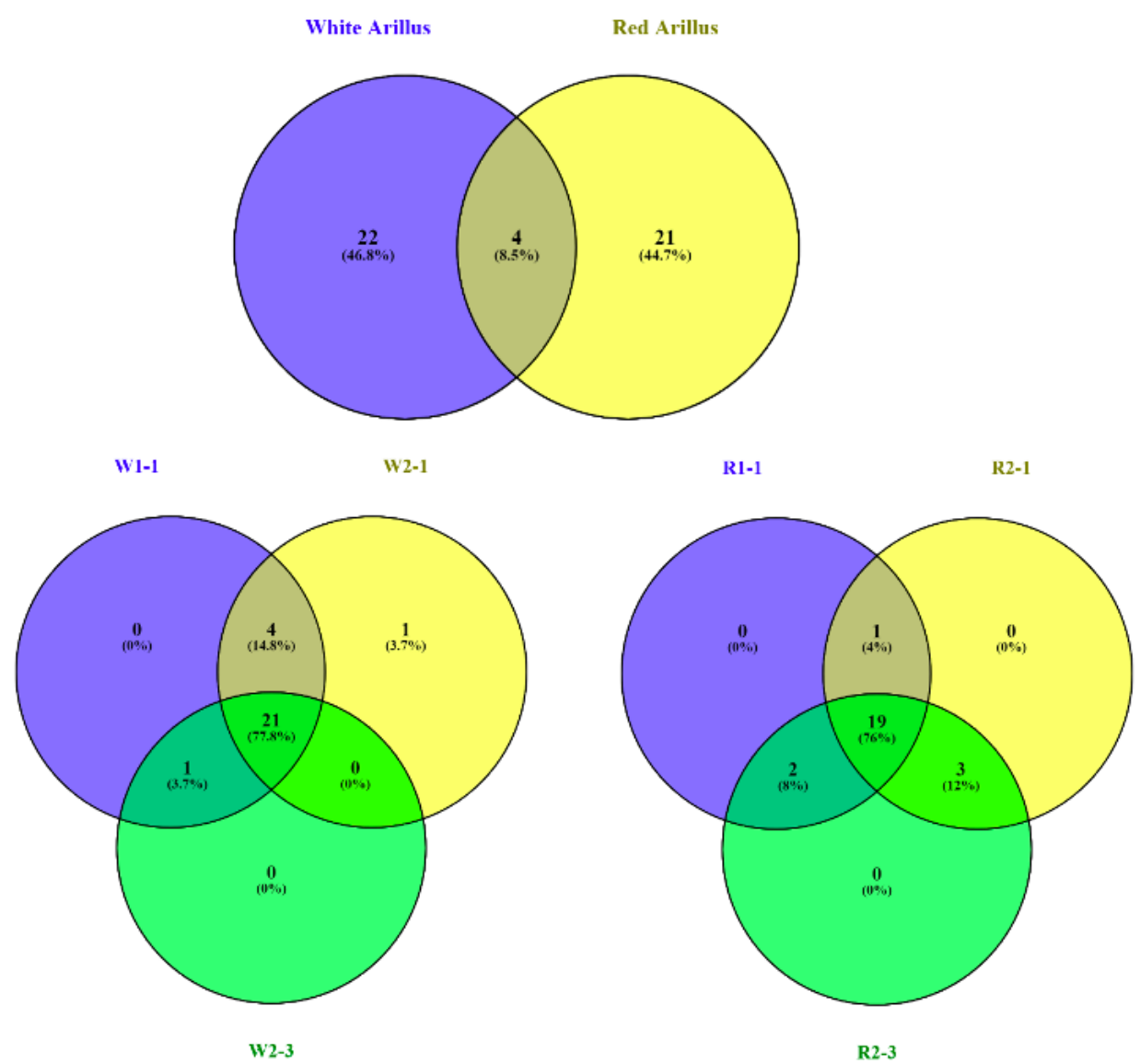

Figure 2. Metabolites-Venn Diagram of white and red arillus accessions of Salacca sumatrana. W1-1, W2-1, and W2-3 were accession refer to white arillus. R1-1, R2-1, and R2-3 was accession refer to white arillus

The highest ranged metabolite concentrations were shown in the boxplot values of phenethyl alcohol, 2furancarboxaldehyde 5- (hydroxymethyl), 4h-pyran-4-one, 2,3-dihydro-3,5-dihydroxy-6-methyl, ethylic acid, 2 furancarboxaldehyde. Phenylethyl alcohol has a value ranging from -10 to 10,2 -furancarboxaldehyde 5(hydroxymethyl) has a value ranging from -8.5 to 9 , $4 \mathrm{~h}$ pyran-4-one, 2,3-dihydro-3,5-dihydroxy-6-methyl has values ranged from -7.5 to 7.5 , ethylic acid had values ranging from -12 to 12,2 -furancarboxaldehyde had values ranging from -11 to 11 (Figure 1). The high range of these five compounds shows variations in the six accessions of salaks in Indonesia.

The expressed metabolites between red and white arillus showed a difference, indicating that the difference in arillus color was influenced by the level of expression of different metabolites. Metabolites that are highly expressed in red arillus $S$. sumatrana include 2-furancarboxaldehyde; 2,3-dihydro-3,5-dihydroxy-6-methyl-4h-pyran; 5 methyl furfural; 2,5-furandione, 3,4-dimethyl; 3-octanone; phenylethyl alcohol; larixinic acid; 2-furanmethanol; 1- (2furyl) -2-hydroxyethanone; benzenol; nicotinyl alcohol; 5formyl-2-furfurylmethanoate; 5-acetoxymethyl-2furaldehyde; cyclohexanecarbo nitrile, 2-hydroxy-, trans; 1-d1-3-cyclohexene-1; octadecanoic acid; stearic acid; 4hpyran-4-one, 2,3-dihydro-3,5-dihydroxy-6-methyl; formic acid, ethyl ester; levulinic acid; 2-acetyl-2-hydroxy.gamma.-butyrolactone; 1-butanol, 3-methyl-, propanoate; 1,4: 3,6-dianhydro-.alpha.-d-glucopyranose; benzoic acid; 2-furancarboxaldehyde, 5- (hydroxymethyl).

\section{Fold change hierarchical differential expression}

Fold change analysis showed 25 upregulated compounds and 21 downregulated compounds in red arillus. Conversely, in white arillus as many as 21 upregulated compounds and 25 downregulated compounds (Figure 3 ). There are three compounds below the threshold value, indicating that these three compounds do not play a role in the formation of color in the arillus in zalacca.

A total of 15 compounds, showed significant VIP values, i.e., ethylic acid; 2-furancarboxaldehyde; phenethyl alcohol; 2-furancarboxaldehyde 5- (hydroxymethyl); 4hpyran-4-one, 2,3-dihydro-3,5-dihydroxy-6-methyl; phenylethyl alcohol; 1- (2-furyl) -2-hydroxyethanone; 2methoxy-4-vinylphenol; 2,4-xylene; 3,4-xylene; 5-formyl2-furfurylmethanoate; benzenol; n-octyl alcohol; butyric acid; and butanoic acid, 2-methyl. Broadly speaking, based on the VIP value, the compounds in the arillus of $S$. sumatrana are divided into three groups, namely low (0.50.75), medium (0.75-1.5), and high (1.5-3.5). Compounds with high VIP value include ethylic acid; 2furancarboxaldehyde; phenethyl alcohol; 2- 
furancarboxaldehyde 5- (hydroxymethyl); 4h-pyran-4-one, 2,3-dihydro-3,5-dihydroxy-6-methyl, indicating that these compounds show a high difference between red and white arillus in $S$. sumatrana. The compound group with moderate VIP value was phenylethyl alcohol; 1- (2-furyl) 2-hydroxyethanone; 2-methoxy-4-vinylphenol; 2,4-xylene, allows this compound to become an intermediate pathway between the red and white arillus in S. sumatrana. The compound group with low VIP value is 3,4-xylene; 5formyl-2-furfurylmethanoate; benzenol; n-octyl alcohol; butyric acid; and butanoic acid, 2-methyl (Figure 4), indicated that this compound had a low effect on arillus color differences.

\section{Analisis PCA and clusterring}

A total of six accessions showed that they were divided into two groups, indicating that the metabolite compounds from GC-MS results in the two types of arillus were very different. Accessions R-1, R-2, and R-3 are grouped into one, namely on-axis -25 , while $\mathrm{W}-1, \mathrm{~W}-2$, and $\mathrm{W}-3$ converge on group two on axis 25 . The population on white arillus is relatively uniform compared to with red arillus, found that the environmental influence on metabolites in red arillus was relatively greater than that in white arillus. PCA-based grouping resulted in a total value of $99.8 \%$ where PC1 was $99.7 \%$ and PC2 was $0.1 \%$, indicating that the resulting grouping had a relatively high percentage.

Based on dendrogram analysis, accessions of R2, R1, and R3 merge into one group, indicating that the population has metabolites that can be used as a differentiator for red arillus in S. sumatrana. On the other hand, accessions W-3, $\mathrm{W}-1$, and $\mathrm{W}-2$ were grouped together and according to their grouping, namely white arillus. The percentage similarity index of the resulting dendrogram ranges from 0 50 (Figure 4).

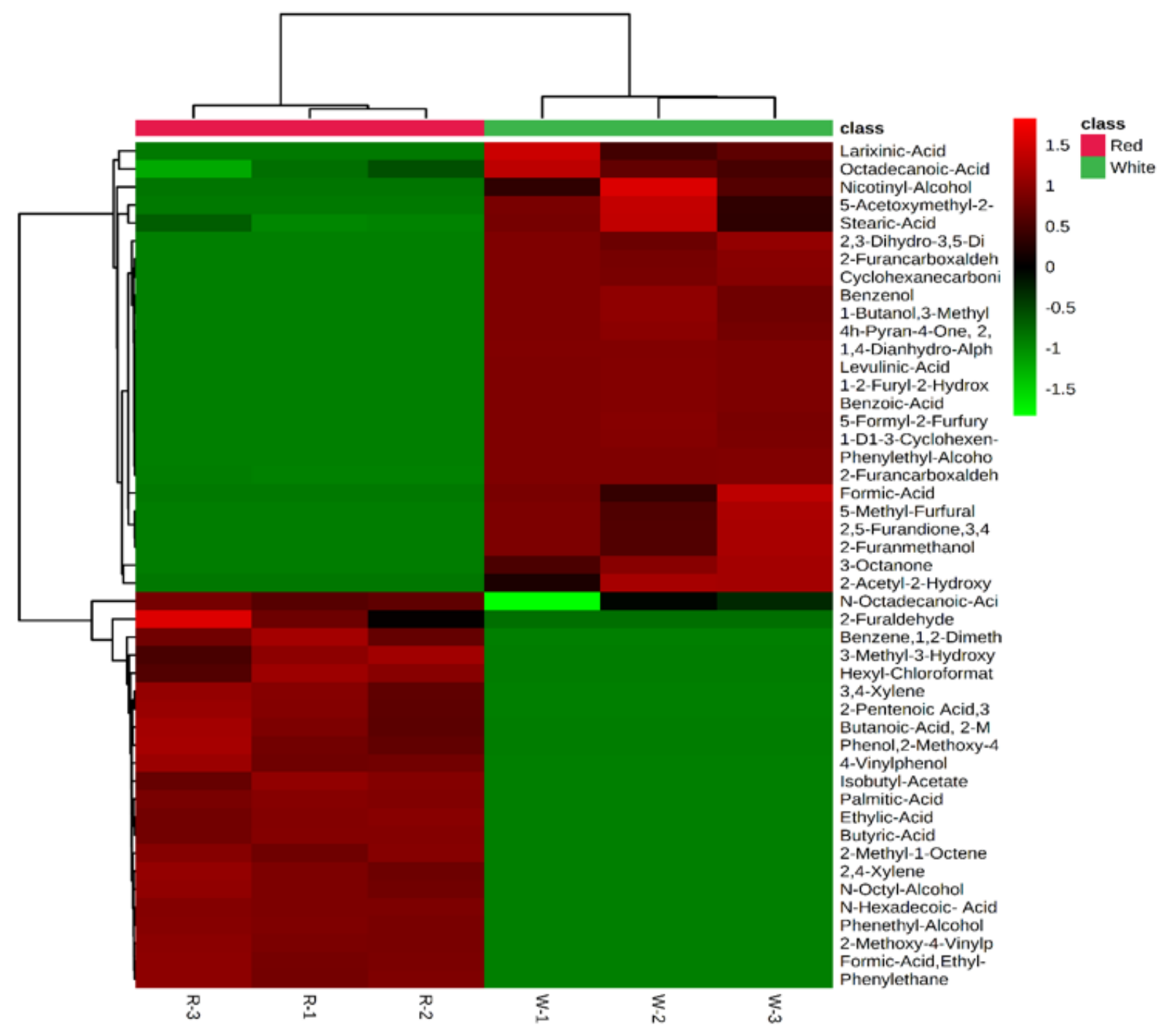

Figure 3. Hierarchical metabolites differential expression among population based on arillus characters. Arillus characters of Salacca sumatrana were divided into red arillus accessions (R1, R2, and R3) and white arillus accessions (W1, W2, and W3). The figure was performed using R.metaboAnalyst followed syntax of Fendiyanto et al. (2020) 

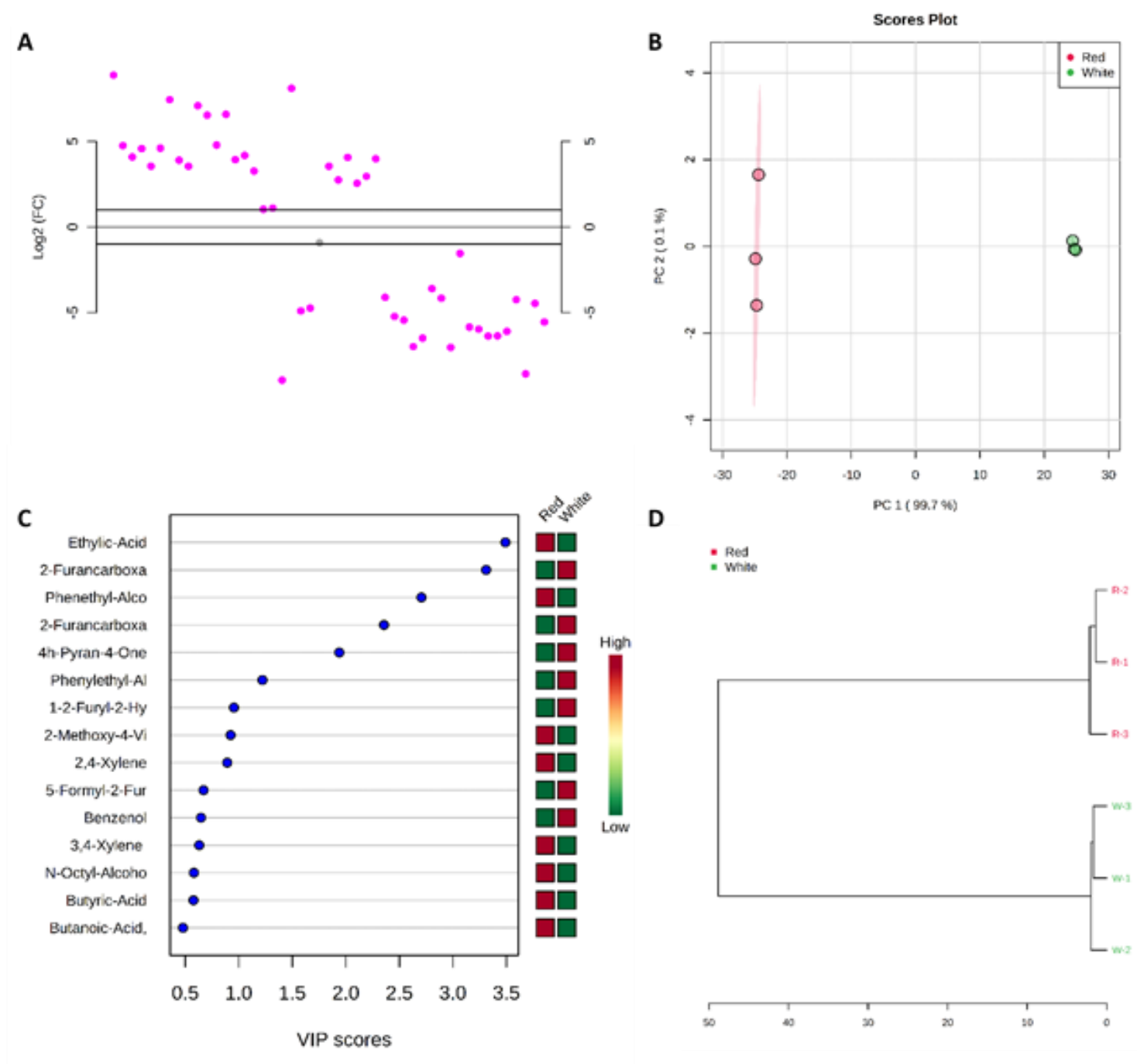

D

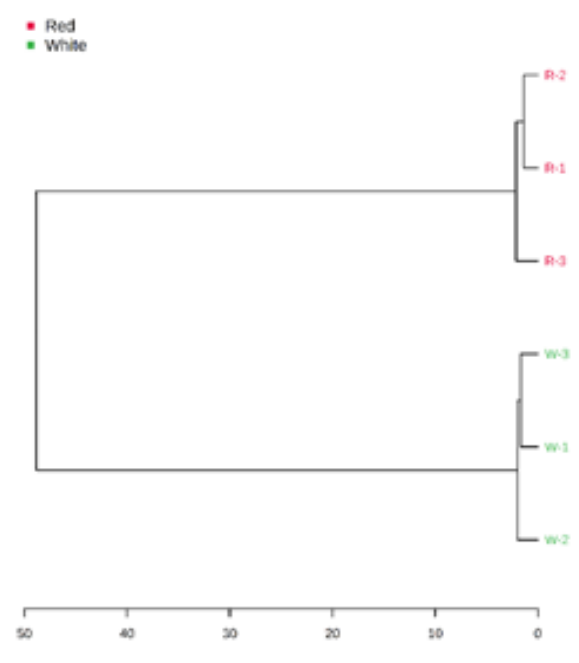

Figure 4. Global fold change and clustering analysis of red/white arillus of Salacca sumatrana. Log2(FC) of red/white arillus. The pink color was similar to upregulated/downregulated of metabolites expressions in red/white arillus ratio. The threshold was set 1 and -1 (A). PCA analysis of six population-based on arillus characters (B). VIP scores of top hits metabolites in red/white arillus of $S$. sumatrana (C). Dendrogram analysis of six populations of S. sumatrana based on metabolites profiling (D)

\section{Intercorrelations among compounds}

In general, the Sperman intercorrelation value shows that metabolites are divided into three correlation groups, namely group I, which consists of positive correlation; group II, which consists of negative correlation; and group III which consists of compounds with positive correlation. Group I consisted of correlations between butyric acid = benzene, 1,2-dimethyl; butyric acid = phenol, 2-methoxy4- (2-propenyl); butyric acid = phenethyl alcohol; butyric acid = butanoic acid, 2-methyl; butyric acid = n-octyl alcohol; butyric acid $=2$-furaldehyde; butyric acid $=2$ methoxy-4-vinylphenol; butyric acid $=2$-pentenoic acid, 3 methyl-, methyl ester; butyric acid $=2,4$-xylene; butyric acid = 3,4-xylene; butyric acid = n-octadecanoic acid; ethylic acid = benzene, 1,2-dimethyl; ethylic acid = phenol, 2-methoxy-4- (2-propenyl); ethylic acid = phenethyl alcohol; ethylic acid = butanoic acid, 2-methyl; ethylic acid $=\mathrm{n}$-octyl alcohol; ethylic acid $=2$-furaldehyde; ethylic acid
= 2-methoxy-4-vinylphenol; ethylic acid $=2$-pentenoic acid, 3-methyl-, methyl ester; ethylic acid $=2,4$-xylene; ethylic acid $=3,4$-xylene; ethylic acid $=$ n-octadecanoic acid; 3-methyl-3-hydroxypentanoic acid $=$ benzene, 1,2dimethyl; 3-methyl-3-hydroxypentanoic acid $=$ phenol, 2 methoxy-4- (2-propenyl); 3-methyl-3-hydroxypentanoic acid $=$ phenethyl alcohol; 3-methyl-3-hydroxypentanoic acid = butanoic acid, 2-methyl; 3-methyl-3hydroxypentanoic acid = n-octyl alcohol; 3-methyl-3hydroxypentanoic acid = 2-furaldehyde; 3-methyl-3hydroxypentanoic 3-methyl-3-hydroxypentanoic acid3methyl-, methyl ester; 3-methyl-3-hydroxypentanoic acid = 2,4-xylene; 3-methyl-3-hydroxypentanoic acid $=3,4-$ xylene; and 3-methyl-3-hydroxypentanoic acid $=\mathrm{n}$ octadecanoic acid. group ii consisted of correlations between 2 -furancarboxaldehyde $=$ butyric acid; 3 -octanone $=$ ethylic acid; larixinic acid = 3-methyl-3hydroxypentanoic acid; cyclohexanecarbonitrile, 2- 
hydroxy-, trans = hexyl chloroformate; 2-furanmethanol = isobutyl acetate; phenylethyl alcohol = palmitic acid; 2,5furandione, 3,4-dimethyl = benzene, 1,2-dimethyl; 5 methyl furfural = phenol, 2-methoxy-4- (2-propenyl); 2,3dihydro-3,5-dihydroxy-6-methyl-4h-pyran = phenethyl alcohol; 2-furancarboxaldehyde, 5- (hydroxymethyl) = butanoic acid, 2-methyl; formic acid = n-octyl alcohol; octadecanoic acid = 2-furaldehyde; stearic acid $=2$ methoxy-4-vinylphenol; nicotinyl alcohol $=2$-pentenoic acid, 3-methyl-, methyl ester; 2-acetyl-2-hydroxy-.gamma.butyrolactone $=2$,4-xylene; 1,4: 3,6-dianhydro-.alpha.-dglucopyranose $=3,4$-xylene; benzoic acid $=$ n-octadecanoic acid; 1-butanol, 3-methyl-, propanoate = 2-methyl-1octene; levulinic acid = n-hexadecoic acid; 4h-pyran-4-one, 2,3-dihydro-3,5-dihydroxy-6-methyl = phenylethane; 1 -d13-cyclohexen-1 = formic acid, ethyl ester; 5acetoxymethyl-2-furaldehyde $=4$-vinylphenol, and others.
Group III consisted of correlations between 2furancarboxaldehyde $=$ octadecanoic acid; 2furancarboxaldehyde $=$ stearic acid; 2-furancarboxaldehyde = nicotinyl alcohol; 2-furancarboxaldehyde = 2-acetyl-2hydroxy-.gamma.-butyrolactone; 2-furancarboxaldehyde $=$ 1,4-dianhydro-.alpha.-d-glucopyranose; 2furancarboxaldehyde = benzoic acid; 2furancarboxaldehyde = 1-butanol, 3-methyl-, propanoate; 2-furancarboxaldehyde = levulinic acid; 2furancarboxaldehyde $=4 \mathrm{~h}$-pyran-4-one, 2,3-dihydro-3,5dihydroxy-6-methyl; 2-furancarboxaldehyde = 1-d1-3cyclohexen-1; 2-furancarboxaldehyde = acetoxymethyl -2furaldehyde; 2-furancarboxaldehyde = 5-formyl-2furfurylmethanoate; 2-furancarboxaldehyde = 1- (2-furyl) 2-hydroxyethanone; 2-furancarboxaldehyde = benzenol, and others (Figure 5).

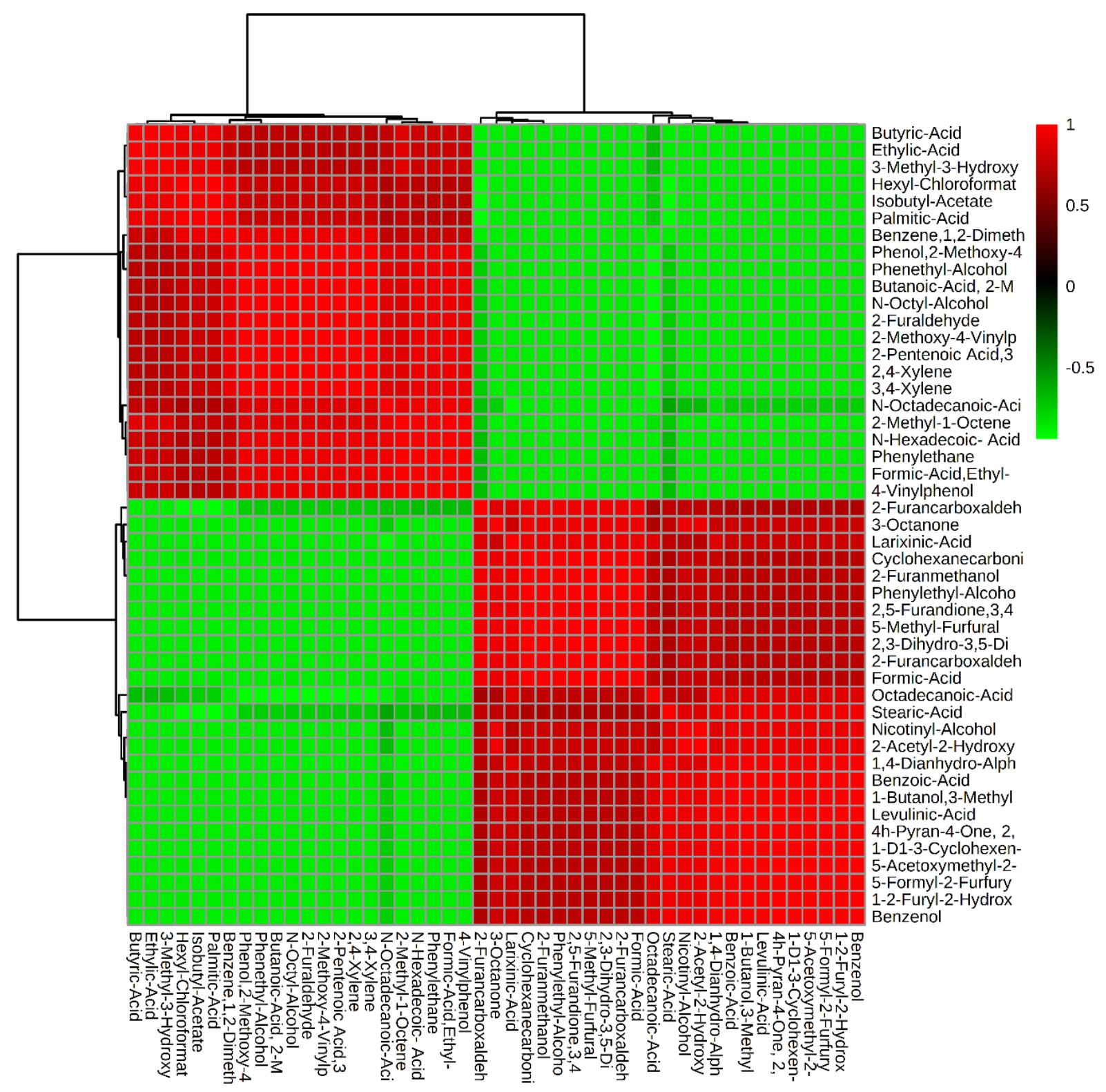

Figure 5. Intercorrelation among metabolites of Salacca sumatrana in red/white arillus 


\section{Discussion}

Salak is a fruit that has an origin of species from the tropics and is very abundant in Indonesia and Malaysia (Aralas et al. 2009). The identified salak consists of three types, namely Sidempuan, Javanese and Balinese salaks. Specifically to Salak Sidempuan (S. sumatrana), metabolomic studies and metabolite differential expression were very few. The first research on metabolomic studies on S. sumatrana is research by Fendiyanto et al. (2020). This study is limited to metabolite profiling and pathway analysis of red arillus tissue only. Meanwhile, it is very important to study differences in metabolite expression, especially by comparing the expression of metabolites in the tissues of white and red arillus because $S$. sumatrana is a species of salak that also has white arillus based on morphological studies (Harahap and Ardiarini 2018). The study of morphological and anatomical markers has been widely studied in other tropical plants such as Desmos sp. (Nikmah et al. 2020) and Cucumis sp. (Pratami et al. 2019). So far, the most popular salak in the market is salak with white arillus especially in species Salacca zalacca, while red arillus is thought to have many properties and is useful for humans (Yuliamita 2014; Saleh et al. 2018; Fendiyanto et al. 2020). Therefore, a comprehensive study to find any potential compounds that can be found in the two networks by looking at the differences in hierarchical differential expression is important.

The important potential compound in the red arillus tissue of $S$. sumatrana is reported to be ethylic acid. Ethylic acid is an important compound for the pathway of the metabolism of sulfur and pyruvic acid (Fendiyanto et al. 2020). However, important compounds in white arillus tissue and their comparison of metabolite expression have not been previously reported. In this study, we confirmed that ethylic acid has a higher metabolite expression in red arillus tissue than in white arillus tissue, this study supports the research of Fendiyanto et al. (2020). Other compounds that have high expression in the red arillus network are $\mathrm{N}$ octadecanoid acid, 2-furaldehyde, 2 pentanoic acid, palmitic acid, and ethylic acid. In contrast, metabolites that have high expression in white arillus tissue are ranxinic acid, nicotinic alcohol, stearic acid, 2-furan carboxaldehyde, and others (Figure 3). The same thing was obtained by Browse and Somerville (1991) and Ragasa et al. (2016) where many lipid compounds play a role in differences in metabolism in plants. The difference in metabolite expression between the red/white arillus allows for genetic and physiological differences (Wang and Benning 2012; Pratami et al. 2020), both of which ultimately lead to phenotypic differences. In the future, compounds of ranxinic acid, nicotinic alcohol, stearic acid, 2-furan carboxaldehyde can be used as metabolite selection markers to differentiate $S$. sumtarana white arillus from another arillus type at an early stage. The use of metabolite selection markers in some plants is very little done, we confirm that in S. sumatrana it can help plant breeders to find markers of $S$. zalacca fruit selection as early as possible.

The difference in metabolite expression in white and red arillus tissue is indicated by differences in the value of $\log 2$ (FC) and is important in fatty acid synthesis (Bates et al. 2007). Based on the fold change study, 24 compounds were upregulated in white arillus, 21 compounds were highly expressed in red arillus, and 3 compounds had relatively no fold change in the two tissues. These three compounds can be used as distinguishing markers at the species level, especially to differentiate $S$. sumatrana species from other salak species. Meanwhile, other compounds can be used as markers to differentiate between white and red arillus tissue in S. sumatrana species. Based on VIP scores, the compounds ethylic acid, phenyl alcohol, 2-methoxy vinyl, 2.4 xylenes, 3,4 xylene, N-octyl alcohol, butyric acid, and butanoic acid are important compounds in the red arillus tissue. In contrast, 2-furan carboxaldehyde, 4h pyran, phenyl ethyl alcohol, 1,2 furyl hydroxyl, 5formyl 2 furan, and benzene are important compounds in white arillus tissue. Ethylic acid phenyl alcohol, 2-methoxy vinyl, 2,4 xylene, 3,4 xylene, N-octyl alcohol, butyric acid, butanoic acid, 2-furan carboxaldehyde, 4h pyran, phenyl ethyl alcohol, 1,2 furyl hydroxyl, 5-formyl 2 furan, and benzene acts as an antioxidant (Kanlayavattanakul 2013; Zaini et al. 2013), plays a role in metabolic processes (Ma et al. 2014; Mancini et al. 2015; Kochian et al. 2015), and plant physiological processes (Ohki 1986; Harwood 1989; Wong and Tie 1993; Harwood 1996; Tsutsui et al. 2011; Goulet et al. 2012; Li et al. 2013; Tyagi and Agarwal 2017).
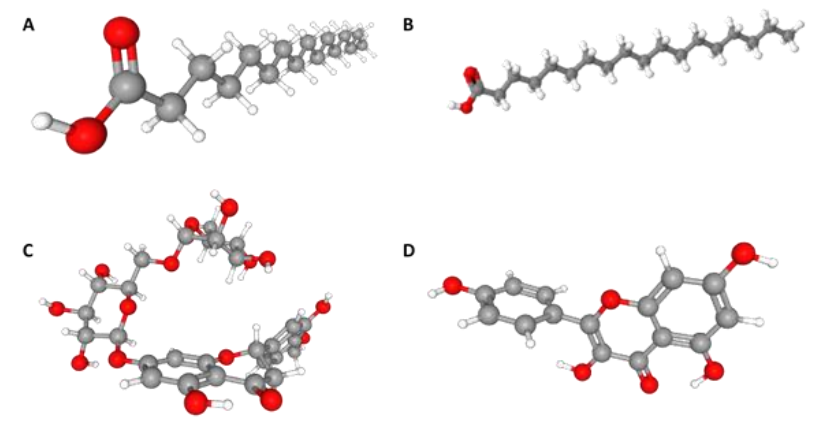

D
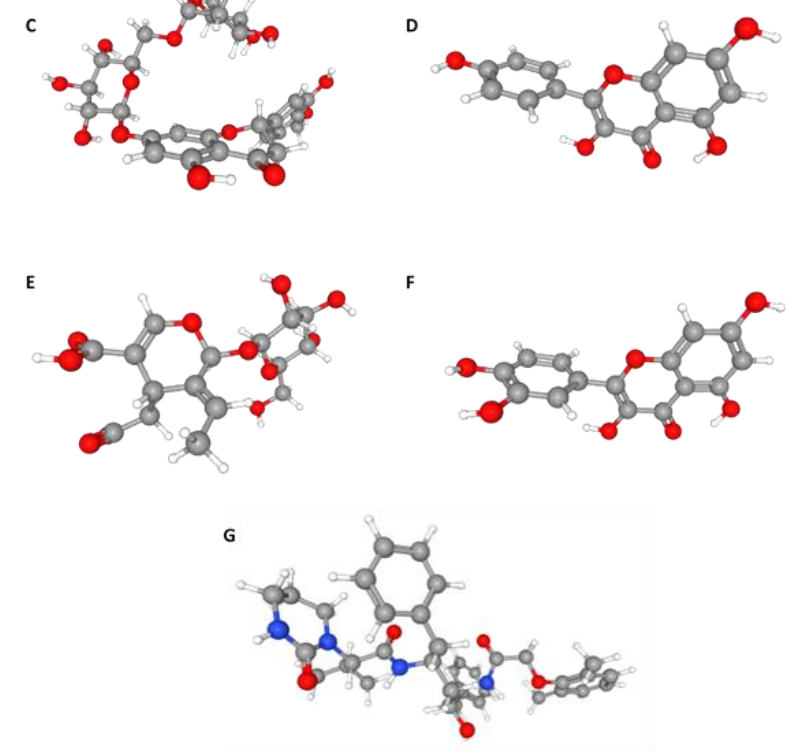

Figure 6. 3D-Crystal structure of potential compounds as a putative antiviral in tropical medicine plant to prevent/inhibit SARS-Cov-2. Palmitic acid (A), Stearic acid (B) Hesperidin (C) Kaempferol (D) Oleoside (E) Quercetin (F) Lopinavir as positive structure/control (G). This image was incorporated from Pubchem. 
The study of molecular docking is important to determine the potential compounds of $S$. sumatrana. This salak is believed to be a medicinal plant and has the potential to have antioxidant, antiaging, and antihyperglycemic activity (Aralas et al. 2009; Priyatno et al. 2012; Saleh et al. 2018). The study of the medicinal plant potential of $S$. sumatrana as an antiviral is tried to be reviewed in this study. Based on preliminary in-silico molecular docking studies, stearic acid and palmitic acid compounds have the potential for compounds to effectively target protein targets in the 3-dimensional structure of SARS-Cov-2(Figure 6, Table 1).
Two compounds that act as antiviral in this study are stearic acid and palmitic acid. Both of these compounds have sufficient binding energy values to inhibit the 3CLPro protein in the SARS-Cov-2 virus. This research also provides preliminary information regarding the study of the potential compounds in the fruit of $S$. sumatrana as a medicinal plant, especially in antiviral activity. The life cycle of the Covid-19 virus begins when the $S$ protein in the virus is attached to an angiotensin-converting enzyme (ACE2) receptor in the human respiratory tract (Xu et al. 2020).

Table 1. Top hits of molecular docking of the potential compound in Salacca sumatrana and other medicinal plants as antiviral against SARS-Cov 2

\begin{tabular}{|c|c|c|c|c|c|c|}
\hline $\begin{array}{l}\text { Compound } \\
\text { ID }\end{array}$ & $\begin{array}{l}\text { Compound } \\
\text { name }\end{array}$ & $\begin{array}{c}\text { Relative } \\
\text { binding energy } \\
\text { (kcal/mol) }\end{array}$ & $\begin{array}{c}\text { Binding } \\
\text { energy } \\
\text { (kcal/mol) }\end{array}$ & Compound structure & Literature & Source \\
\hline SS1 & Palmitic acid & 1.39 & -8.02 & & In this study & Salacca sumatrana \\
\hline SS2 & Stearic acid & 1.33 & -8.08 & & In this study & Salacca sumatrana \\
\hline OP1 & Hesperidin & 0.69 & -8.72 & & $\begin{array}{l}\text { Trujillo-Correa et al. } \\
\text { (2019) } \\
\text { Parhiz et al. (2015) }\end{array}$ & $\begin{array}{l}\text { Psidium guajava, } \\
\text { Citrus aurantium }\end{array}$ \\
\hline OP1 & Kaempferol & 0.90 & -8.51 & & $\begin{array}{l}\text { Widyowati and Agil } \\
\text { (2018) }\end{array}$ & Zingiber aromaticum \\
\hline OP1 & Oleoside & 2.89 & -6.52 & & Yanuar et al. (2014) & Jasminum sambac \\
\hline OP1 & Quercetin & 0.85 & -8.56 & & Nair et al. (2015) & Clitoria ternatea \\
\hline $\mathrm{CP}$ & Lopinavir & 0.00 & -9.41 & & Erlina et al. (2020) & $\begin{array}{l}\text { Drugs as SARS-Cov- } \\
2 \text { putative antiviral }\end{array}$ \\
\hline
\end{tabular}


The positive thread of the RNA genome from the virus enters the cell, and it is possible to synthesize the viral device through replication and translation. The virus that is formed then undergoes exocytosis and allows it to infect other cells. The important structure of the virus, namely the 3D structure of SARS-CoV-2 main protease (3CLPro), is reported to be inhibited by compounds contained in medicinal guava and citrus plants based on a molecular docking study by Erlina et al. (2020). This study adds to the findings that $S$. sumatrana as a tropical medicinal plant also has the potential as a protein protease inhibitor in the SARS-Cov-2 virus based on this preliminary molecular docking study. However, it needs to be verified to completely understand the potential report in the future, particularly using in vivo and clinically experiment in the laboratory.

In conclusion, S. sumatrana is a tropical fruit that has many benefits, including containing anti-oxidant compounds, cancer prevention, anti-inflammatory, and increasing immunity. This study confirms the discovery of several potential compounds that can be used as preventive measures in overcoming several diseases, particularly as herbal and antivirus.

\section{ACKNOWLEDGEMENTS}

This research was partially funded by financial support from the Ministry of Agriculture of the Republic of Indonesia through Didi Darmadi and the Ministry of Defense, the Republic of Indonesia through Indonesia Defense University, Bogor, Indonesia. This work has also supported by the Ministry of Research, Technology, and Higher Education through Dr. Miftahul Huda Fendiyanto and Dr. Rizky Dwi Satrio year 2014-2015. The authors acknowledged Laboratorium Kesehatan Daerah (LABKESDA, BSL3), Jakarta, Indonesia for their assist and help, particularly in GC-MS analysis.

\section{REFERENCES}

Aralas S, Mohamed M, Fadzelly ABM. 2009. Antioxidant properties of selected salak (Salacca zalacca) varieties in Sabah, Malaysia. Nutr Food Sci 39 (3): 243-250.

Bates PD, Ohlrogge JB, Pollard M. 2007. Incorporation of newly synthesized fatty acids into cytosolic glycerolipids in pea leaves occurs via acyl editing. J Biol Chem 282 (43): 31206-31216. DOI: 10.1074/jbc.M705447200.

Browse J, Somerville C. 1991. Glycerolipid synthesis: Biochemistry and regulation. Ann Rev Plant Physiol 42: 467-506.

Chong J, Soufan O, Li C, Caraus I, Li S, Bourque G, Wishart DS, Xia J. 2018. MetaboAnalyst 4.0: Towards more transparent and integrative metabolomics analysis. Nucl Acids Res 46 (1): 486-494. DOI: 10.1093/nar/gky310.

Chong J, Wishart DS, Xia J. 2019. Using MetaboAnalyst 4.0 for comprehensive and integrative metabolomics data analysis. Curr Protoc Bioinformatics 68 (1): e86. DOI: 10.1002/cpbi.86.

Chong J, Xia J. 2018. MetaboAnalystR: An R package for flexible and reproducible analysis of metabolomics data. Bioinformatics 27 (24): 4313-4314. DOI: 10.1093/bioinformatics/bty528.

Do Amaral MN, Arge LWP, Benitez LC, Danielowski R, da Silveira Silveira SF, da Rosa Farias D, de Oliveira AC, da Maia LC, Braga EJB. 2016. Comparative transcriptomics of rice plants under cold, iron, and salt stresses. Funct Integr Genomics 16 (5): 567-579. DOI: 10.1007/s10142-016-0507-y.

Erlina L, Paramita RI, Kusuma WA, Fadilah F, Tedjo A, Pratomo IP, Ramadhanti NS, Nasution AK, Surado FK, Fitriawan A, Istiadi KA, Yanuar A. 2020. Virtual screening on Indonesian herbal compounds as COVID-19 supportive therapy: Machine learning and pharmacophore modeling approaches. Res Square 3 (29): 1-35. DOI: 10.21203/rs.3.rs-29119/v1.

Fendiyanto MH, Satrio RD, Darmadi D. 2020. Metabolic profiling and pathway analysis in red arillus of Salacca sumatrana demonstrate significant pyruvate, sulfur, and fatty acid metabolisms. Biodiversitas 21 (9): 4361-4368. DOI: 10.13057/biodiv/d210955.

Fendiyanto MH, Satrio RD, Suharsono, Tjahjoleksono A, Hanarida I, Miftahudin. 2019b. QTL for aluminum tolerance on rice chromosome 3 based on root length characters. SABRAO J Breed Genet 51 (4): 451-469.

Fendiyanto MH, Satrio RD, Suharsono, Tjahjoleksono A, Miftahudin. 2019a. Correlation among Snpb11 markers, root growth, and physiological characters of upland rice under aluminum stress. Biodiversitas 20 (5): 1243-1254. DOI: 10.13057/biodiv/d200514.

Goulet C, Mageroy MH, Lam NB, Floystad A, Tieman DM, Klee HJ. 2012. Role of an esterase in flavor volatile variation within the tomato clade. PNAS 109 (46): 19009-19014.

Harahap GP, Ardiarini NR. 2018. The variability of Padang Sidempuan snake fruit types (Salacca sumatrana) based on morphological characters and analysis isoenzymes. Jurnal Produksi Tanaman 6 (5): 922-929. [Indonesian]

Harwood JL. 1989. Lipid metabolism. CRC Crit Rev Plant Sci 8: 1-43.

Harwood JL. 1996. Recent advances in the biosynthesis of plant fatty acids. BBA-Lipids Lipid Metab 1301: 7-56.

Hiremath SS, Sajeevan RS, Nataraja KN, Chaturvedi AK, Chinnusamy V, Pal M. 2017. Silencing of fatty acid desaturase (FAD7) gene enhances membrane stability and photosynthetic efficiency under heat stress in tobacco (Nicotiana benthamiana). IJEB 55: 532-541.

Jorge TF, Rodrigues JA, Caldana C, Schmidt R, van Dongen JT, ThomasOates J, Antonio C. 2016. Mass spectrometry-based plant metabolomics: Metabolite response to abiotic stress. Mass Spectrom Rev 35: 620-649. DOI: 10.1002/mas.21449

Joyard J, Douce R. 1987. Galactolipid Synthesis. In Lipids: Structure and Function. Academic Press, New York.

Kanlayavattanakul M, Lourith N, Ospondpant D, Ruktanonchai U, Pongpunyayuen S, Chansriniyom C. 2013. Salak plum peel extract as a safe and efficient antioxidant appraisal for Cosmetics. Biosci Biotechnol Biochem 77 (5): 1068-1074. DOI: 10.1271/bbb.130034.

Kochian LV, Pĩneros MA, Liu J, Magalhaes JV. 2015. Plant adaptation to acid soils: The molecular basis for crop aluminum resistance. Annu Rev Plant Biol 66: 571-598. DOI: 10.1146/annurev-arplant-043014114822 .

Lander JP. 2014. R for Everyone: Advanced Analytics and Graphics. Addison-Wesley, Boston.

Li F, Li S, Li HB, Deng GF, Ling WH, Wu S, Chen F. 2013. Antiproliferative activity of peels, pulps, and seeds of 61 fruits. J Funct Foods 5 (3): 1298-1309. DOI: 10.1016/j.jff.2013.04.016.

Ma JF, Chen ZC, Shen RF. 2014. Molecular mechanisms of Al tolerance in gramineous plants. Plant Soil 381: 1-12

Mancini A, Imperlini E, Nigro E, Montagnese C, Daniele A, Orrù S, Buono P. 2015. Biological and nutritional properties of palm oil and palmitic acid: Effects on health. Molecules 20: 17339-17361. DOI: 10.3390/molecules200917339

Mastrangelo A, Ferrarini A, Rey-Stolle F, García A, Barbas C. 2015. From sample treatment to biomarker discovery: A tutorial for untargeted metabolomics based on GC-(EI)-Q-MS. Anal Chim Acta 900: 21-35. DOI: 10.1016/j.aca.2015.10.001.

Nguyen BD, Brar DS, Bui BC, Nguyen TV, Pham LN, Nguyen HT. 2003. Identification and mapping of the QTL for aluminum tolerance introgressed from the new source, Oryza rufipogon Griff., into indica rice (Oryza sativa L.). Theor Appl Genet 106: 583-593. DOI: 10.1007/s00122-002-1072-4.

Nguyen VT, Burow MD, Nguyen HT, Le BT, Le TD, Paterson AH. 2001. Molecular mapping of genes conferring aluminum tolerance in rice (Oryza sativa L.). Theor Appl Genet 102: 1002-1010. DOI: 10.1007/s001220000472.

Nikmah IA, Rugayah R, Chikmawati T. 2020. Leaf anatomical variation in Desmos Lour. and Dasymaschalon (Hook.f.\&Thomson) Dalla 
Torre \& Harms species (Annonaceae). Biodiversitas 21 (7): 3317 3330. DOI: $10.13057 /$ biodiv/d210756.

Ohki K. 1986. Photosynthesis, chlorophyll, and transpiration responses in aluminum stressed wheat and sorghum. Crop Sci 26: 572-575. DOI: 10.2135/cropsci1986.0011183X002600030030x.

Pang Z, Chong J, Li S, Xia J. 2020. MetaboAnalystR 3.0: Toward an optimized workflow for global metabolomics. Metabolites 10 (5): 180-186. DOI: 10.3390/metabo10050186.

Parhiz H, Roohbakhsh A, Soltani F, Rezaee R, Iranshahi M. 2015. Antioxidant and anti-inflammatory properties of the Citrus flavonoids hesperidin and hesperetin: An updated review of their molecular mechanisms and experimental models. Phytother Res 29 (3): 323-331. DOI: $10.1002 /$ ptr.5256.

Park SE, Seo SH, Kim EJ, Byun S, Na CS, Son HS. 2019. Changes of microbial community and metabolite in kimchi inoculated with different microbial community starters. Food Chem 274: 558-565. DOI: $10.1016 /$ j.foodchem.2018.09.032.

Pratami MP, Chikmawati T, Rugayah R. 2019. Short Communication: Further morphological evidence for separating Mukia Arn. from Cucumis L. Biodiversitas 20 (1): 211-217. DOI 10.13057/biodiv/d200124.

Pratami MP, Chikmawati T, Rugayah R. 2020. Genetic diversity of Cucumis and Mukia (Cucurbitaceae) based on ISSR markers. SABRAO J Breed Genet 52 (2): 127-143.

Pratami MP. 2020. Biosistematika marga Cucumis dan Mukia (Cucurbitaceae) di Malesia [Disertation]. Institut Pertanian Bogor, Bogor, Indonesia. [Indonesian]

Priyatno LHA, Sukandar EY, Ibrahim S, Adnyana IK. 2012. Antihyperuricemic effect of ethanol extract of snake fruit (Salacca edulis Reinw) var. Bongkok on wistar male rat. J Food Sci Eng 2: 271-276.

Quinet M, Vromman D, Clippe A, Bertin P, Lequeux H, Dufey I, Lutts S, Lefèvre I. 2012. Combined transcriptomic and physiological approaches reveal strong differences between short-and long-term response of rice (Oryza sativa) to iron toxicity. Plant Cell Environ 35 (10):1837-1859. DOI: 10.1111/j.1365-3040.2012.02521.x.

Ragasa CY, Ting JU, Ramones MV, Carmen MST, Lerom RR, Linis VC. 2016. Chemical constituents of Salacca wallichiana mart. Int J Curr Pharm Rev Res 7 (4): 186-189.

Saleh MSM, Siddiqui MJ, Mediani A, Ismail NHN, Ahmed QU, So'ad SZM, Saidi-Besbes S. 2018. Salacca zalacca: A short review of the palm botany, pharmacological uses and phytochemistry. Asian Pac J Trop Med 11 (12): 645-652.
Satrio RD, Fendiyanto MH, Suharsono, Supena EDJ, Miftahudin. 2019. Identification of drought-responsive regulatory genes by hierarchical selection of expressed sequence tags and their expression under drought stress in rice. Int J Agric Biol 22 (6): 1524-1532.

Tsutsui T, Yamaji N, Ma JF. 2011. Identification of a cis-acting element of ART1, a $\mathrm{C} 2 \mathrm{H} 2$-type zinc-finger transcription factor for aluminum tolerance in rice. Plant Physiol 156 (2): 925-931. DOI: 10.1104/pp.111.175802.

Tyagi T, Agarwal M. 2017. Phytochemical screening and GC-MS analysis of bioactive constituents in the ethanolic extract of Pistia stratiotes L. and Eichhornia crassipes (Mart.) Solms. J Pharmacogn Phytochem 6 (1): 195-206.

Wang Z, Benning C. 2012. Chloroplast lipid synthesis and lipid trafficking through ER-plastid membrane contact sites. Biochem Soc Trans 40 (2): 457-463. DOI: 10.1042/BST20110752.

Wishart DS, Feunang DY, Marcu A, Guo AC, Liang K, Vazquez-Fresno R, Sajed T, Johnson D, C L, Karu N. 2017. HMDB 4.0: The human metabolome database for 2018. Nucleic Acids Res 46: 608-617. DOI: 10.1093/nar/gkx1089.

Wong KC, Tie DY. 1993. Volatile constituents of salak (Salacca edulis Reinw.) fruit. Flavour Frag J 8 (6): 321-324.

Xia J, Wishart DS. 2016. Using MetaboAnalyst 3.0 for comprehensive metabolomics data analysis current protocols in bioinformatics. Curr Protoc Bioinformatics 55: 14.10.1-14.10.91. DOI: 10.1002/cpbi.11.

Xu X, Chen P, Wang J, et al. 2020. Evolution of the novel coronavirus from the ongoing Wuhan outbreak and modeling of its spike protein for risk of human transmission, Sci China Life Sci 63 (3): 457-460. DOI: 10.1007/s11427-020-1637-5.

Yanuar A, Suhartanto H, Mun'im A, Anugraha BH, Syahdi RR. 2014. Virtual screening of Indonesian herbal database as HIV-1 Protease inhibitor. Bioinformation $10 \quad$ (2): 52-55. DOI: 10.6026/97320630010052.

Yuliamita A. 2014. Keragaman jenis salak bangkalan (Salacca zallaca (Gaetner) Voss) menggunakan penanda morfologi dan analisis isozim. Jurnal Produksi Tanaman 3 (1): 35-42. [Indonesian]

Zaini NAM, Osman A, Hamid AA, Ebrahimpour A, Saari N. 2013. Purification and characterization of membrane-bound polyphenol oxidase (mPPO) from snake fruit [Salacca zalacca (Gaertn.) Voss]. Food Chem 136 (2): 407-414.

Zhang L, Li G, Wang M, Di D, Sun L, Kronzucker HJ, Shi W. 2018. Excess iron stress reduces root tip zone growth through nitric oxidemediated repression of potassium homeostasis in Arabidopsis. New Phytol 219 (1): 259-274. DOI: 10.1111/nph.15157. 